\title{
Para superar o divórcio entre economia e sociedade: diagnóstico crítico e notas propositivas em um contexto de pandemia
}

To overcome the divorce between economy and society: critical diagnosis and propositional notes in a pandemic context

\author{
Genauto Carvalho de França Filho ${ }^{1}$ \\ André Magnelli ${ }^{2}$ \\ Philippe Eynaud ${ }^{3}$
}

\begin{abstract}
RESUMO
O presente artigo se propõe a pensar a relação entre economia e sociedade em tempos de pandemia. O artigo inicia com (I) um diagnóstico crítico-analítico das causas e razões do divórcio entre economia e sociedade, identificando suas origens históricas e, ao mesmo tempo, buscando esclarecer como opera sua lógica na forma do neoliberalismo contemporâneo e como ela está em contradição com a democracia e, mesmo, com os próprios valores liberais. Em seguida (II), refletimos sobre as consequências do divórcio entre economia e sociedade, cujas insustentabilidades geradas serão analisadas tanto no nível macro-estruturante - ambientais, sócioeconômicas e políticas -, como no nível meso- e microssocial - territoriais e subjetivas. Por fim (III), passamos para as notas propositivas" a favor de uma retomada da relação entre economia e sociedade, onde propomos reformulações conceituais e analíticas aptas para abrir um horizonte de sociedade do pós-bem estar social e também para formular, operacionalmente, um desenho de políticas públicas voltadas para o desenvolvimento solidário de territórios.
\end{abstract}

Palavras chave: Economia e sociedade; desenvolvimento; solidariedade democrática; territórios.

\begin{abstract}
This article proposes to think about the relationship between economy and society in times of pandemic. The article begins with (I) a critical-analytical diagnosis of the causes and reasons for the divorce between economics and society, identifying its historical origins and, at the same time, seeking to clarify how its logic operates in the form of contemporary neoliberalism and how it is in contradiction with democracy and even with liberal values themselves. Then (II), we reflect on the consequences of the divorce between economy and society, whose unsustainability generated will be analyzed both at the macro-structuring level - environmental, socio-economic and political - as well as at the meso- and microsocial level - territorial and subjective. Finally (III), we move on to the propositional notes" in favor of a resumption of the relationship between economics and society, where we propose conceptual and analytical reformulations capable of opening a horizon of post-welfare social society
\end{abstract}

\footnotetext{
1 Professor Titular da UFBA, pesquisador CNPq (DT-II), coordenador do Núcleo de Pós-Graduação em Administração (NPGA/UFBA) e da Incubadora Tecnológica de Economia Solidária e Gestão do Desenvolvimento Territorial (ITES/UFBA). E-mail: francafilhogenauto2@gmail.com.

${ }^{2}$ Professor adjunto da Faculdade de São Bento do Rio de Janeiro. Diretor da Instituição de livre estudos e pesquisa Ateliê de Humanidades (RJ). E-mail: prof.andremagnelli@gmail.com.

3 Professor da Université Paris 1 - Panthéon-Sorbonne (Institut d'Administration d'Entreprises - IAE), França. E-mail: philippe.eynaud@univ-paris1.fr.
}

Artigo Convidado para compor este Fórum Especial em Democracia, Políticas Públicas e COVID-19. Agradecemos aos autores a participação neste debate tão urgente. 
and also to formulate, operationally , a design of public policies aimed at the solidarity development of territories.

Keywords: Economy and society; development; democratic solidarity; territories.

\section{Introdução}

A pandemia do COVID-19 explicitou um divórcio que já existia de modo implícito, mas que era ocultado com insistência: aquele entre economia e sociedade. Em alguns países do mundo, como o Brasil e os Estados Unidos, ele se manifestou no discurso público pelo suposto conflito entre duas urgências: a de manter a atividade econômica e a de proteger a saúde da população. Este conflito corresponde àquele outro, muito comum, que consiste em separar a esfera política da esfera econômica, fazendo com que o debate social seja mantido entre uma concepção de mundo orientada para ideais democráticos e outra que reivindica a prioridade absoluta das questões econômicas. Essas polaridades são profundamente prejudiciais, pois sugerem que a democracia e mesmo o direito à vida, à saúde e a um ambiente saudável seriam obstáculos para um bom desenvolvimento econômico, de tal forma que poderia parecer indispensável - até mesmo inevitável - a dissociação entre tais esferas (HILLENKAMP, LAVILLE, 2013). Todavia, quando observamos mais atentamente, percebemos que mais importante do que uma suposta contradição entre, de um lado, a necessidade econômica de lucro, emprego e renda e, de outro, o imperativo de proteger e promover a saúde da população - ou entre, de um lado, a lógica estritamente econômica do mercado e, de outro, os anseios por uma organização democrática dos processos de reprodução da vida e da sociedade - está a emergência da questão (e prática) da solidariedade, que ao nosso ver é a chave capaz de reatar o nó górdio entre economia e vida, democracia e economia.

Se as sociedades humanas foram capazes de produzir na modernidade muito mais opulência e riqueza material do que as anteriores, seu nível de empobrecimento continua recrudescente e, mais ainda, elas estão hoje colocando em risco a própria possibilidade de vida humana e não-humana diante dos efeitos ambientais gerados pela lógica de seu desenvolvimento. Ou seja, há um profundo paradoxo que caracteriza a dinâmica do desenvolvimento econômico que, apesar de dar sinais mais visíveis em tempos de crise como os atuais, é contudo um elemento constitutivo da sua própria formação. E, talvez, em um contexto catastrófico de pandemia, não apenas as suas insustentabilidades se tornam mais evidentes e insuportáveis, como também as soluções a serem propostas se tornam mais plausíveis, aceitáveis e, até mesmo, como efetivamente necessárias diante do estado de coisas.

Nosso argumento consiste em pensar que o paradoxo atual do desenvolvimento moderno está intimamente relacionado à forma, inédita historicamente, pela qual a economia se relaciona com a sociedade. Neste sentido, o artigo inicia com (I) um diagnóstico crítico-analítico das causas e razões do divórcio entre economia e sociedade, identificando suas origens históricas e, ao mesmo tempo, buscando esclarecer como opera sua lógica na forma do neoliberalismo contemporâneo e como ela está em contradição com a democracia e, mesmo, com os próprios valores liberais. Em seguida (II), refletimos sobre as consequências desse divórcio, cujas insustentabilidades geradas serão analisadas tanto no nível macro-estruturante ambientais, sócio-econômicas e políticas -, como nos níveis meso e microssocial - afetando a territorialidade e a produção de subjetividades. Por fim (III), passamos para as "notas propositivas" a favor de uma retomada da relação entre economia e sociedade, onde sugerimos reformulações conceituais e analíticas aptas para abrir um horizonte de sociedade do pós-bem estar social e também para formular, operacionalmente, um desenho de políticas públicas voltadas para o desenvolvimento solidário de territórios.

E deste modo cremos ter realizado uma itinerário completo em que a teoria se articula com a prática. Tendo começado com um diagnóstico das crises que vivemos e com uma análise crítica dos mecanismos que as geram e radicalizam, chegamos em uma reformulação de qual quadro de entendimento da realidade deve 
nos guiar a fim de terminarmos com um desenho de agenda renovada de visão e prática da ação pública.

\section{Diagnóstico crítico-analítico: causas e razões do divórcio entre economia e sociedade}

\section{O mercado autorregulado e a autoproteção da sociedade}

Os tempos modernos produziram uma separação entre economia e sociedade até então desconhecida na história das sociedades humanas. De fato, a invenção do mercado autorregulador (POLANYI, 1986 [1944]), que ocorre na esteira da Revolução Industrial, marca esse divórcio. Sua principal característica é de pretender existir prescindindo da própria sociedade, isto é, desenraizada ou autonomamente. Diferentemente das demais formas de economia, que estão submetidas às regras de organização da vida social, este mecanismo inverte a relação histórica entre economia e sociedade, em nome de uma reivindicação de liberdade bastante específica. Dessa vez é a sociedade que deve estar submetida às regras da economia compreendida exclusivamente como mercado. A condição para tanto seria a submissão de qualquer tipo de relação ou de atividade humana ao mecanismo de compra e venda sob condições mercantis. É precisamente quando até a terra, o trabalho e o dinheiro (consideradas como mercadorias fictícias pois não se produzem) se submetem à lógica da mercadorização, que podemos sublinhar a passagem de economias com (ou sem) mercado para economias de mercado. O destino das economias de mercado, conforme notou Polanyi, é de tornarem-se sociedades de mercado, devido à extensão sem fim das relações baseadas no interesse privado individual (FRANÇA FILHO, LAVILLE, 2020).

Esse mecanismo, justificado pela promessa de crescimento ilimitado, é em realidade profundamente paradoxal: possui capacidades extraordinárias de criação de riqueza e, ao mesmo tempo, notável poder destrutivo dessa mesma riqueza, devido ao seu caráter concentrador que gera a produção incessante de desigualdades sociais. Essa é razão pela qual esse movimento de expansão sem limites do mercado encontra historicamente a resistência da própria sociedade através de variadas expressões da proteção social (FRANÇA FILHO, LAVILLE, 2020). Sendo esta tratada como um empecilho ao desenvolvimento das forças de mercado, a história do capitalismo pode ser lida como um processo de tensionamento permanente entre esse mecanismo econômico tentando subordinar a sociedade à sua racionalidade, e a sociedade, por sua vez, lutando para se proteger através da preservação de garantias na forma de direitos. Em sendo tais garantias representada pelo chamado Estado Democrático de Direito, aqueles que se inclinam, nesse movimento pendular, mais para a defesa da expansão dos mercados irão se posicionar também numa relação difícil com a democracia.

\section{O neoliberalismo contra a democracia}

O distanciamento entre neoliberalismo e democracia constitui um primeiro ponto frágil na base de sustentação do divórcio entre economia e sociedade. É comum, desde os anos 1980, confundir-se a complexa tradição do liberalismo moral e político com as propostas neoliberais sintetizadas programaticamente no chamado "consenso de Washington" (HARVEY, 2005). Contudo, o neoliberalismo é uma versão reduzida da tradição dos liberalismos. Formulado por autores como Friedrich Hayek e Milton Friedman, sob inspiração de Ludwig von Mises, tal doutrina tem origem na crítica econômica e ideológica do socialismo burocrático e estatista. Na virada dos anos 1970 para o 1980, na esteira da crise fiscal, cultural e política dos Estados de Bem Estar Social, ele encontra uma aplicação governamental com Thatcher na Inglaterra e Reagan nos EUA e, partir de então, difunde-se publicamente por agências como FMI e Banco Mundial enquanto receituário para lidar com as crises fiscais do "Terceiro Mundo". Além disso, ele corresponde a uma reação conservadora, cultural e politicamente, aos novos movimentos sociais emergentes nos anos 1950 e 1960. Tendo em vista que havia se identificado à crítica do comunismo, o neoliberalismo pareceu conquistar seu triunfo final com a queda do Muro de Berlim e o colapso do 
totalitarismo, tornando-se desde então um senso comum associar livre-mercado com democracia, como se o mercado autorregulado, combinado com instituições políticas representativas, fosse o garantidor e realizador de uma sociedade liberal-democrática.

Todavia, existem razões históricas e sociológicas para que seja afirmado o contrário. Em primeiro lugar, é justamente contra o excesso de democracia que se batem os textos de Hayek e Friedman, ao argumentarem que a dinâmica de democratização de movimentos sociais, tais como os ecológicos e feministas, engendraria desordem e ineficiência. Além disso, não parece desnecessário lembrar que, anos antes, Mises já havia se pronunciado a favor do fascismo; e que o principal laboratório dos Chicago Boys, liderado por Milton Friedman, foi a severa ditadura do General Pinochet no Chile. Independentemente das escolhas pessoais e dos fatos históricos, o que importa é que o projeto neoliberal é, senão essencialmente antidemocrático, ao menos destruidor da democracia. Quando o neoliberalismo transforma o mercado autorregulado na instituição que "garantiria" as demais liberdades (econômicas, morais, políticas e sociais), as liberdades e os direitos vão se tornando cada vez mais destruídas pelas leis "naturais" e formais de oferta/ procura, que se tornam imperativos sistêmicos aos quais todos devem se adaptar. Desta forma, a livreiniciativa econômica e os princípios de associação se tornam cada vez menos possíveis de se realizar, porque a tendência será a desorganização da sociedade e a oligarquização dos mercados. E quando a doutrina neoliberal se torna um projeto político institucional, como o foi no Chile de Pinochet, é quase impossível que avance em um contexto de liberdades democráticas, porque ele depende de restrições da democracia, ou mesmo de uma ditadura, que impeçam reações de proteção aos danos oriundos do mercado e de reivindicação de direitos individuais e sociais.

Se tais evidências são reveladoras do divórcio entre mercado autorregulado e democracia, é fundamental ressaltar também que o neoliberalismo preconiza a reorganização inteira da sociedade em torno do princípio da concorrência, graças às autoridades públicas adquiridas no e pelo mercado. Com isso, ele tenderá a avançar na transformação dos diversos aspectos da vida humana e não-humana em "mercadorias fictícias" e, para a realização de tal propósito, Ihe serão necessárias uma justificação moral acerca do que seja a natureza do humano e uma forma de selecionar os humanos que the sejam mais adequados.

\section{Um darwinismo social: a seleção "natural" do homo economicus}

O fato do neoliberalismo marcar profundamente nossas sociedades nas últimas décadas deve-se não apenas à sua dimensão econômica. Ele também se constituiu como um verdadeiro projeto antropológico. Como mostrou Polanyi, o que resulta da "naturalização" dos mercados é tanto uma desorganização da sociedade, quanto uma degradação do humano. O seu homem é o homo economicus, cujas paixões se tornam meros interesses egoístas e cuja razão se reduz ao cálculo estritamente utilitarista (CAILLÉ, 1989; HIRSCHMAN, 2002). A lógica da sociedade neoliberal atua pela "seleção natural" de indivíduos e organizações tidos como "eficientes", isto é, que sejam bem sucedidos na luta pela sobrevivência em uma ordem competitiva pela aquisição de lucro, com a predominância de uma racionalidade utilitarista de instrumentalização do outro e de si mesmo visando a conquista de espaço e duração no tempo. Como mostra o próprio Polanyi e outros autores (como PICHOT, 2001), o darwinismo social emerge neste processo como a ideologia que justifica o sistema, dando aos "vencedores" as virtudes de uma adaptação bem sucedida e aos perdedores a responsabilidade pelo seu fracasso (são os losers, para usarmos a lógica econômico-corporativa do mainstream anglo-saxônico). Com isso, o egoísmo se torna "nobre" e os valores "nobres" se tornam inúteis; o acúmulo material vira sinal de sucesso e a existência da pobreza, um mal necessário da natureza das coisas.

Mas como um sistema caracterizado pelo tão elevado nível de risco que impõe a sociedade pôde se justificar? A suposta naturalização do egoísmo buscou respaldo tanto em bases teológicas quanto em registros supostamente científicos. A título de ilustração, a moral do auto-interesse disseminada pela 
Reforma Protestante teve papel decisivo ao legitimar um ethos utilitarista que preconiza a capacidade de uma sociedade se regular prescindindo da solidariedade. Nesta visão, as esperanças estão depositadas na capacidade de livre iniciativa dos sujeitos em buscar o melhor para si, numa espécie de comunhão de egoístas garantidora da estabilidade da ordem social mais ampla, onde "vícios privados seriam virtudes públicas", como diz Mandeville (LATOUCHE, 2001). O raciocínio benthamiano consistia em pensar que se cada um buscasse satisfazer seus interesses egoístas, a sociedade encontraria seu equilíbrio e felicidade geral de todos (CLERO, 2001). Em uma versão menos radical, também Smith deposita grandes esperanças, em sua Teoria dos sentimentos morais, na simpatia do comerciante capaz de contribuir com esse equilíbrio. Porém, numa versão mais radical, a interpretação feita do trabalho de Darwin sobre a seleção natural é aquela que ficou mais conhecida. Tal como a suposta concorrência no reino da natureza, cuja seleção natural valoriza os mais aptos ou mais capazes e torna meritório o êxito individual, a vida social deveria ter o mesmo destino. Porém, este "enobrecimento do egoísmo" parece mais uma interpretação imprecisa da tese de Darwin do que propriamente um dado da realidade efetiva. Em primeiro lugar, por tratar-se de uma abordagem que retira de Darwin a importância da colaboração como uma condição presente em seu conceito de seleção natural. Em segundo lugar, porque deixa de reconhecer aquilo que está muito mais presente no "reino da natureza": a colaboração (SERVIGNE, CHAPELLE, 2017).

A generalização de um comportamento individualista em tempos atuais, parece assim menos um dado de alguma suposta natureza humana, e mais uma condição humana definida pela disseminação de valores que passam a ser fortalecidos como uma construção sócio-política, sócio-cultural e sócio-histórica. Conforme nos advertia Marcel Mauss (2003 [1924], p. 307), "o homo oeconomicus não está atrás, está adiante de nós". Inclusive, poderíamos dizer, de forma provocativa, que o neoliberalismo é não apenas uma ideologia construída historicamente, como também uma utopia "negativa" (uma "distopia"), porque, quando implementada, revela-se como um pesadelo. Mas, felizmente, o neoliberalismo não se realizou de forma plena em nossas sociedades, apesar de sua forte hegemonia cultural nas últimas décadas. Isso se deve, em parte, aos mecanismos de autoproteção da sociedade mencionados acima. De todo modo, ele fortaleceu projetos econômico-políticos e processos sociais e culturais que conduziram ao atual divórcio entre economia e sociedade, que possui graves consequências econômicas, sociais, ecológicas e individuais, geradoras de um mundo insustentável.

\section{Vivendo em um mundo insustentável: as consequências do divórcio}

O divórcio entre economia e sociedade é subjacente e se apresenta invisibilizado pelas análises econômicas tout court. Porém, constitui um elemento estruturante da dinâmica do desenvolvimento em escala mundial, ao redefinir os termos da relação entre economia e desenvolvimento. Seus efeitos podem ser compreendidos em pelo menos três dimensões: uma mais macrossocial, que é estruturante no plano institucional, e outras duas no plano micro e meso-social, afetando as dinâmicas territoriais e as subjetividades individuais e coletivas. Essas três dimensões encontram-se absolutamente indissociáveis e a distinção aqui tem apenas propósito analítico-pedagógico.

\section{A dimensão macro-estruturante e as instabilidades em curso}

De fato, as características que conformam a dinâmica econômica no capitalismo contemporâneo definem seus efeitos sobre a sociedade, ou seja, sobre o desenvolvimento. A principal característica da dinâmica econômica contemporânea é seu elevado grau de financeirização (DOWBOR, 2017). Tal fenômeno representa um deslocamento do principal centro de produção de valor ou daquilo que vulgarmente é chamado de "riqueza econômica": da atividade produtiva concreta para o mercado financeiro. Com isso, aquilo que é nomeado comumente de "economia real" se torna subordinada à lógica de reprodução e ampliação de um capital especulativo e rentista que é desterritorializado e mundializado. 
Três aspectos conjugados orientam as preocupações atuais com o efeito de tal dinâmica sobre o desenvolvimento das sociedades: (a) seus impactos ambientais e ecológicos decorrentes; (b) sua incapacidade de generalização do bem-estar social para a maioria da população; e (c) sua elevada concentração do poder decisório mundial fora de instituições públicas. Estes três fatores articulados conformam algumas das dimensões da nossa crise atual, que pode ser definida, no nível macroestruturante, como uma tripla insustentabilidade: ambiental, socioeconômica e política (FRANÇA FILHO, 2019).

(a)Do ponto de vista socioambiental, os níveis de consumo desenfreados como consequência da necessidade de crescimento ilimitado produz um efeito de exaustão sobre os recursos naturais. Isso gera uma grande crise ambiental que se verifica através do aquecimento climático e uma série de outros indicadores como desmatamento, poluição dos oceanos, contaminação química dos nossos solos e água, e destruição da biodiversidade (IPCC, 2014; IPBES, 2017). Alguns cientistas da Terra e ecologistas mencionam uma "grande aceleração" ocorrida desde os anos 1970 - que coincide, portanto, com o avanço do modelo neoliberal -, o que nos conduz, provavelmente, a um looping de catástrofes ambientais já fora do controle. Desta forma, com a entrada nos tempos de "antropoceno", a humanidade está diante da necessidade de transformações imediatas tanto no nível da economia quanto no das formas de vida (BONNEUIL \& FRESSOZ, 2013).

(b) Já do ponto de vista socioeconômico, a principal característica da atual dinâmica de desenvolvimento é a produção de níveis cada vez mais crescentes de desigualdade. Em um dos estudos internacionais recentes mais conhecidos sobre a dinâmica do capital no século XXI, o economista francês Thomas Piketty demonstra com profundo rigor essa escalada ao evidenciar os graus cada vez maiores de desigualdade socioeconômica na dinâmica histórica do capitalismo e que se acentuam nas três últimas décadas (PIKETTY, 2013; CAPRARA, 2017). Juntamente com Piketty, uma série de outros estudos que vêm evidenciando o aumento da desigualdade (EPSTEIN, MONTECINO, 2016; OXFAM, 2017) salientam sua origem vinculada à concentração de renda e de riqueza no planeta. Logo, a abordagem do tema da desigualdade descortina uma nova lógica econômica, re-atualizando a problemática da apropriação. Ela está associada a uma reconfiguração das relações entre tempo-espaço, o que tende a fragmentar e estratificar as localidades, regiões e nações em função de suas inserções em redes de produção e fluxos de capital distribuídos por todo o globo.

(c) A lógica de apropriação desigual das riquezas e da desterritorialização da produção e das finanças está, obviamente, na origem de um enfraquecimento da capacidade de organização da vida econômica e de promoção dos direitos por parte dos Estados-nação. Isso gera uma terceira dimensão da crise, de natureza eminentemente política. Trata-se do fato das sociedades contemporâneas estarem confrontadas a uma nova forma de governança internacional, cuja principal característica é o deslocamento tácito do poder decisório mundial de um lócus público, representado pelos Estados e organismos supranacionais, para o setor privado, representado pelo poder real dos poucos grandes grupos corporativos, baseados sobretudo no capital financeiro, cujas atividades estão espalhadas nos mais diversos países (DOWBOR, 2017; CHOMSKY, 2017). A proporção do endividamento público dos Estados nacionais no mundo aumenta em uma medida praticamente simétrica ao crescimento econômico desses gigantes corporativos mundiais, que aliás, tornam-se seus credores. Tal fenômeno acontece, ainda, na mesma proporção do enfraquecimento das instâncias supranacionais de decisão no mundo. Com o poder econômico concentrado em gigantes corporativos transnacionais, os Estados-nação se encontram em situação de dependência em relação a estes atores considerados como investidores, sendo suas políticas públicas diretamente influenciadas por estes (DOWBOR, 2017). Com a fragilização da soberania dos países, são as próprias democracias que se encontram então ameaçadas.

De todo modo, não é apenas por causa da fragilidade das instituições políticas estatais-nacionais que as democracias tendem a se enfraquecer; pois o projeto neoliberal também gera efeitos insustentáveis sobre 
os territórios, as subjetividades e a comunidade política, de forma a estar na fonte da atual ascensão dos movimentos populistas.

\section{A dimensão meso e microssocial: efeitos sobre territórios e subjetividades}

No nível meso-social, percebemos como um capitalismo financeirizado e desterritorializado atua sobre as dinâmicas locais e regionais. O território fica dependente desse modelo econômico. De um lado, observase que se realiza uma retirada dos poderes deliberativos e decisórios dos territórios (locais, regiões e nações) para situá-los no interior de corporações transnacionais, agências internacionais e mercados financeiros globalizados. O poder dos investidores externos, dos CEOs e dos escritórios de governança global subordina assim o processo de desenvolvimento local, de forma a minar as possibilidades de endogenia na dinâmica local e territorial. Neste sentido, ocorre uma invisibilização dos poderes decisórios das organizações e, também, das suas capacidades de influenciar as instituições políticas. De outro lado, percebe-se que essa mesma racionalidade atua sobre as localidades e regiões reconfigurando-as segundo uma lógica abstrata do investimento especulativo e da mercantilização, de tal modo que remodelam as cidades e os campos em função de suas conexões com redes internacionalizadas. Juntamente com a ascensão das "cidades globais", temos uma fragmentação interna das metrópoles e municipalidades, com um esvaziamento do espaço cívico nas cidades e uma organização espaço-temporal voltada para a circulação de pessoas e mercadorias tendo em vista experiências de consumo e entretenimento. Todavia, na contramão de um esperado conformismo hedonista, surgem sintomas de esgotamento do modelo neoliberal, que estão presentes não apenas nos sinais visíveis de seu fracasso - como a explosão de desigualdades sociais e da violência, o aumento do custo de vida, os mecanismos de favelização e gentrificação, o desencaixe entre as necessidades das comunidades, cidadãos e trabalhadores locais e as dinâmicas privadas e públicas de investimento e oferta de empregos, equipamentos e serviços -, como também nos sinais indiretos, como o mal-estar generalizado diante da perda de qualidade de vida, a dissolução de relações de confiança e de reconhecimento entre atores locais e a sensação de impotência das comunidades e dos indivíduos em face ao desenvolvimento econômicos, social e político de suas próprias localidades.

Estes sintomas de esgotamento do projeto neoliberal se fazem presentes também no nível microssocial, com seus efeitos sobre a subjetividade e o tipo de individualidade que ele, ao mesmo tempo, supõe e promove. Com a cultura neoliberal, desenvolve-se um hiperindividualismo customizado pelo e para o mercado. O ideal de uma sociedade de concorrência generalizada, em que os indivíduos devem ser empreendedores de si mesmos e responsáveis pelo seu próprio sucesso ou fracasso, produz ao menos três efeitos perversos. Em primeiro lugar, estamos diante de uma sociogênese em massa de transtornos psiquiátricos tais como os de ansiedade, síndromes de pânico e quadros depressivos, em que, como mostra Byung-Chul Han, a "sociedade da performance" vira uma "sociedade do cansaço" (HAN, 2010). Em segundo lugar, o projeto neoliberal modela as subjetividades à sua imagem e semelhança, fazendo ascender traços (ou estruturas) de personalidade de cunho narcisista ou, mesmo, perverso, o que gera graves problemas para uma economia e moral baseadas em princípios associativistas, reciprocitários e comunitários. Este fato se deve à existência de uma contradição entre as subjetividades fomentadas pela sociedade de consumo e as demandas cidadãs por uma democracia que depende de um interesse efetivo pela coisa pública e de competências de participação deliberativa na formação da vida associativa. Em terceiro lugar, a democracia tende a se voltar contra si mesma, como diz Marcel Gauchet (2002), fazendo nascer também novas formas de "personalidades autoritárias", lembrando aquelas dos tempos dos fascismos (ADORNO, 2019 [1950]; MARCUSE, 2015 [1964]). Quando percebemos a conjunção, de um lado, do esvaziamento subjetivo da experiência democrática com, de outro, a ascensão das desigualdades e dos sentimentos de injustiça social, compreendemos como surge uma economia dos afetos negativos - de ressentimento, impotência e ódio -, que são os pavios prontos a serem acesos por movimentos populistas ansiosos a alastrar seus anseios 
incendiários regressivos (MAGNELLI, MAIA \& CAMPOS, 2019; ROSANVALLON, 2020). Neste sentido, as insustentabilidades territorial e cultural retroalimentam as insustentabilidades socioeconômica e política.

\section{Cenários de uma sociedade do pós-bem estar social: para retomar a relação entre economia e sociedade}

Pelas consequências discutidas no tópico anterior, a questão que nos ocupa neste momento é sobre como repensar a relação entre economia e sociedade, de modo a se vislumbrar uma relação entre economia e desenvolvimento que não comprometa a própria vida em sociedade. Para tanto, o pressuposto básico que aqui assumimos consiste em ampliar nossa compreensão acerca de um dos termos centrais dessa relação, a economia.

\section{Reformulações conceituais}

\section{O legado da antropologia econômica}

Neste esforço de ampliação, sugerimos a adoção de um olhar antropológico, pois este busca compreender o funcionamento da economia na história e em diferentes culturas. Aprender com a história e com outras culturas representa uma fonte de inspiração valiosa para esta difícil tarefa de pensarmos soluções inéditas para grandes dilemas da atualidade. Mais especificamente, o legado do acervo de conhecimentos contidos no campo da antropologia econômica nos oferece ao menos quatro contribuições relevantes no esforço em repensarmos o que é o econômico (FRANÇA FILHO, 2019).

Em primeiro lugar, esse legado sublinha a impossibilidade de separar o estudo da economia das demais dimensões que organizam a vida em sociedade, como as relações sociais, políticas, culturais ou ambientais, o que permite concluir sobre a importância do enraizamento da economia na sociedade. Em segundo lugar, esse olhar nos mostra a diversidade das formas de instituição da economia na vida em sociedade, conforme a ênfase sobre a noção de "princípios do comportamento econômico" em Polanyi (1986 e 2012), como o mercado, a redistribuição, a reciprocidade e a domesticidade. Tal abordagem nos permite concluir sobre a irredutibilidade da ideia de economia com relação à ideia de mercado e, mais ainda, nos permite identificar a diferença entre mercado autorregulado (sistema de mercado ou ainda economia de mercado), de um lado, e mercado concreto, do outro. Em terceiro lugar, isso nos conduz a uma concepção mais ampla de economia, entendida como definição substantiva do econômico em Polanyi (2012). Esta permite pensar a economia como a variedade das formas institucionais de interação entre os seres humanos e entre esses e a natureza na busca pela garantia da suas condições materiais de sobrevivência, de subsistência ou de sustentabilidade. Essa concepção reafirma a questão da materialidade na vida em sociedade como o problema primordialmente econômico (da humanidade), mas não separa a produção econômica da reprodução social. Pela diversidade dos princípios econômicos que tal definição inclui, ela se compreende no sentido de envolver ou ultrapassar aquilo que seria sua concepção rival, conhecida como "definição formalista de economia" (POLANYI, 2012). Essa reduz o entendimento da ação econômica ao comportamento maximizador nas condições de funcionamento de um mercado autorregulado, valorizando então as premissas da escassez e da ação puramente racional dos agentes.

\section{A fecundidade do conceito de economia plural}

Desse conjunto de ideias, deduzimos a noção de economia plural enquanto um esforço de re-atualização dessa outra visão do econômico. Como vimos, a definição substantiva do econômico, por ser ampliada, engloba a definição formalista. Da mesma forma, o conceito de economia plural envolve ou ultrapassa a noção de economia de mercado. Nessa relação, a noção de economia plural parece cumprir um propósito 
analítico-normativo, conforme esclarece a dupla acepção do verbo conter. Em um primeiro sentido, a economia plural contém a ideia de mercado, pois este é apenas parte de uma concepção mais ampla. Em um segundo sentido, a economia plural contém a economia de mercado em termos de refrear seus efeitos de externalidade negativa ou barrar sua pretensão de subordinar a sociedade à sua lógica (FRANÇA FILHO, 2019; EYNAUD, FRANÇA FILHO, 2019).

Neste sentido, a fecundidade heurística do conceito de economia plural pode se situar numa reatualização do olhar sobre as dinâmicas econômicas contemporâneas para pensar novas possibilidades de desenvolvimento, segundo pelo menos três matrizes analíticas: a) o de permitir entender a especificidade de distintas lógicas socioeconômicas; b) o de permitir entender as possibilidades de articulação entre tais lógicas, apontando caminhos inovadores em termos de arranjos institucionais; e c) o de permitir ressignificar as próprias práticas de mercado, através de inovações institucionais nos próprios modos de produzir, comercializar, consumir e se relacionar financeiramente (FRANÇA FILHO, 2019). De todo modo, um aspecto de grande relevância, neste esforço de atualização conceitual da ideia do econômico através da noção de economia plural, consiste precisamente em pensar a relação de cada uma das formas de economia com a democracia. É um imperativo de solidariedade democrática que acompanha a proposição de uma outra ideia de economia contida na noção de economia plural. Se ela nos ajuda a refletir sobre outro modo de enxergar o funcionamento da economia real, pelo menos três níveis indissociavelmente articulados podem ser vislumbrados (FRANÇA FILHO, 2019).

Um primeiro nível mais micro-sistêmico consiste em identificar práticas organizativas no seio da sociedade, baseado em mecanismos de solidariedade econômica, como uma projeção miniaturizada do conceito mais amplo de economia plural. Isto porque tais práticas podem ser vistas com ênfase nos modos de gestão de diferentes lógicas em tensão nas respectivas dinâmicas organizativas que são analisadas. Nessas, enfatizase o desafio da busca do equilíbrio necessário à sustentabilidade de tais práticas, em meio à tensão entre as lógicas mercantil, não mercantil e não monetária. Isso significa reconhecer que uma mesma iniciativa, a exemplo de um empreendimento no seu funcionamento cotidiano, pode estar mobilizando recursos simultaneamente: via atividade de comercialização e contraprestação financeira (lógica mercantil), via financiamento público governamental ou não governamental (lógica não mercantil ou redistributista) ou via relações de solidariedade na forma de ajuda mútua, contribuições voluntárias, produção para autoconsumo, mutualização de recursos, entre outros (lógica não monetária ou reciprocitária). Neste sentido, o desafio da gestão encontra-se em manter a lógica mercantil subordinada à lógica solidária.

Um segundo nível mais meso-sistêmico consiste em identificar o potencial de fortalecimento da dinâmica local-territorial do desenvolvimento contida na articulação entre os vários princípios de ação econômica, entre a lógica redistributista, a lógica reciprocitária e a lógica do mercado ressignificado. Se tal abordagem implica em pensar a pluralidade das formas de economia a serviço do seu contexto territorial, é porque existe um valor importante em cada uma dessas formas de economia e um campo aberto de possibilidades para pensar sua articulação segundo as características específicas e demandas de cada contexto. As diferentes redes e parcerias institucionais possíveis neste caso devem obedecer aos pressupostos básicas da democracia e da solidariedade como condição para sua inovação territorial e institucional.

Num terceiro nível, mais macro-sistêmico, o conceito de economia plural pode nos ajudar a melhor compreender a relação entre estado, mercado e sociedade em termos de novas formas de regulação sócioeconômicas. Trata-se nesse caso de superar enfoques funcionais, que tentam entender a regulação a partir de setores, para valorizar uma abordagem mais sociopolítica sobre o papel ressignificado do mercado, do Estado e, sobretudo, da sociedade, na provisão de bens e serviços de modo mais acessível ao conjunto da população. 


\section{Reterritorializar a economia}

Um outro modo de reformulação conceitual pressupõe inverter os termos da relação entre economia e sociedade, bem como aquele da relação entre economia e democracia. Uma economia que esteja, de fato, a serviço da sociedade requer a construção de mecanismos ou dispositivos democráticos de decisão sobre esse redesenho. Se tais mecanismos podem ser vistos como dispositivos institucionais, eles pressupõem um lócus fundamental de existência. Este, justamente, só se define territorialmente. O conceito de território adquire então uma importância vital (França Filho, 2019). A ideia de território, a partir de diferentes acepções (local, comunitário, regional etc.), deve requalificar a prática do desenvolvimento. Enquanto um conceito próprio, tal ideia foi assimilada à ciência geográfica durante o século XX e apresenta distintas abordagens. Sua difusão tem ocorrido juntamente com a noção de territorialidade: "A territorialidade significa relações políticas de governança, sem deixar de envolver processos econômicos, culturais e diferentes formas de apropriação e uso do ambiente. Nesta abordagem, há uma especificidade vinculada ao entendimento do território enquanto espaço de mobilização e luta política em favor da conquista da autonomia decisória" (SAQUET, 2014, p. 176).

Assim, o estudo da territorialidade ou de cada território constitui um elemento básico num esforço renovado de reflexão sobre a relação entre economia e desenvolvimento de modo a retomar a relação de ambos com a sociedade. Lugar de mediação, o território modela essa relação, ao passo que também é por ela modelado, conforme as distintas sobredeterminações: do global ao local. Assim, a tarefa de repensar o sentido do econômico numa agenda renovada de visão sobre o desenvolvimento, não se elabora como pura abstração: ela se constrói a partir das demandas expressas pela territorialidade (FRANÇA FILHO, 2019).

\section{Retomar a solidariedade pública e democrática}

Como dissemos no início deste artigo, existe uma tendência atual de dissociação entre a defesa do econômico e a da democracia. A visão de mundo centrada numa dissociação entre o econômico e o democrático, de tal forma que enfatiza o primeiro em detrimento do segundo, reduz a solidariedade à expressão filantrópica de alguns grandes mecenas oriundos do mundo comercial. Ao fazer isso, construímos um acordo geral ideológico em torno da ideia absurda de que seria normal ter que escolher entre economia e vida. Como vimos, Polanyi $(1986,2011)$ recusa essa observação falaciosa e, baseado em uma rica análise histórica e antropológica, propõe seu conceito de economia de substantiva, que estende o campo econômico - além das trocas de mercado - às lógicas de redistribuição, reciprocidade e domesticidade. Além disso, Polanyi nos ajuda a entender melhor os desafios enfrentados pelos perigos abertos pelas mudanças climáticas e pela perda de biodiversidade. Ao identificar três estágios históricos no processo de mercantilização do mundo (trabalho, dinheiro, natureza), Polanyi nos mostra a extensão da economia de mercado à sociedade de mercado. Assim, ele destaca a perda de nossa capacidade coletiva de preservar os bens comuns (OSTROM, 1990, 2005). Polanyi chama trabalho, dinheiro e natureza de "bens fictícios" porque esses três elementos nunca foram produzidos para serem bens. No entanto, o trabalho de ficção que os rodeia acaba por considerá-los bens. Isso os faz escapar de todas as formas de controle social e democrático. Como resultado, o mundo está em perigo porque a economia tem capacidade de comprometer a própria vida.

Desta forma, Polanyi reabilita, no campo da análise, a solidariedade pública como uma ferramenta na confluência de questões políticas e econômicas, e nos fornece as bases para uma reformulação da economia política. Essa estrutura conceitual nos permite construir a supramencionada economia plural, o que é feito na encruzilhada das diferentes lógicas descobertas com - no final - uma economia intrinsecamente ao serviço da vida (HART, LAVILLE, CATTANI, 2010). Através desta reformulação analítica, torna-se possível pensar em uma solidariedade democrática que esteja em oposição à solidariedade filantrópica. 
A solidariedade democrática é entendida em uma reciprocidade igualitária e em tomadas de decisão abertas e compartilhadas (LAVILLE, EYNAUD, 2019). Uma das características mais marcantes das formas emergentes de solidariedade econômica, indicada através da noção de outra economia, diz respeito à centralidade da dimensão democrática. Ela faz assim referência às práticas de auto-organização de grupos constituídos enquanto coletivos nos seus respectivos territórios e que se voltam à resolução de problemas concretos afetando seu cotidiano de vida. Diferentes temáticas têm emergido nos últimos anos para tentar refletir tais práticas: economia solidária, gestão de bens comuns, inovação social ou democracia econômica (EYNAUD, FRANÇA FILHO, 2019).

Essa dimensão democrática estabelece uma singularidade importante das novas formas de solidariedade. Em primeiro lugar, em relação às formas tradicionais de solidariedade, ao se constituir como uma solidariedade que se abre sobre um espaço público e se baseia na adesão livre e voluntária dos sujeitos. Em segundo lugar, em relação às formas de solidariedade filantrópicas, que não se baseiam em mecanismos democráticos de ação e optam por mecanismos exclusivamente tecnocráticos de decisão. Para aprofundar o potencial dessas novas formas de solidariedade numa agenda renovada de visão e prática do desenvolvimento, torna-se imperativo pensar o potencial dessas novas práticas na construção simultânea de redes, de diferentes tipos e formas, e de processos de governança democrática (EYNAUD, 2015; EYNAUD, FRANÇA FILHO, 2019).

Neste sentido, vale lembrar a reivindicação de Burawoy (2013) por uma sociologia crítica e pública para fortalecer o tecido de uma sociedade civil. Agora, sem dúvida, devemos estabelecer o elo entre a grande transformação prevista por Polanyi (1944), a pesquisa sobre o comum (EYNAUD, LAVILLE, 2018) e os estudos sobre transição e sustentabilidade (FOSSATI, DEGRAVE, LÉVESQUE, 2019). É nessas condições que poderemos explorar sob uma nova luz os conceitos de reforma e revolução em face a um mundo de tecnicidade avançada. Diante da elevada influência da inovação técnica em nossas sociedades, sem dúvida precisamos compensar a falta de conhecimento em termos de inovação social (LAVILLE, KLEIN, MOULAERT, 2017) e de tecnologias sociais (HENRIQUES, ADDOR, MALINA, ALVEAR, 2018). Mas esse programa de pesquisa permanecerá incompleto se não conseguirmos vincular a transição ecológica e social à democratização da economia e à "uma outra gestão" (EYNAUD, FRANÇA FILHO, 2019).

\section{Do conceitual ao operacional}

Após reabilitar as noções de economia e solidariedade, destacamos sua vinculação tanto com o território quanto com a democracia neste esforço de ampliação do olhar. É assim que a reterritorialização econômica e sua democratização constituem pressupostos de base numa proposição renovada em termos de ação pública. Submetemos à discussão neste momento um desenho possível em termos de esboço de política pública, que busca traduzir de modo aplicado (e implicado) a operacionalização do conceito de economia plural, juntamente com a requalificação da noção de solidariedade.

\section{Propondo um desenho: esboço de política de gestão solidária dos territórios}

As grandes linhas de uma tal política se desenham segundo dois níveis estratégicos e quatro eixos de intervenção (conforme figura 1 abaixo). Importa salientar que sua aplicação toma como referência uma dada territorialidade. 
Quadro 2 - Eixos e níveis estratégicos na gestão territorial solidária.

\begin{tabular}{|c|c|}
\hline Níveis Estratégicos & Eixos de Intervenção \\
\hline \multirow{2}{*}{ Reconstrução Institucional } & 2 - Princípio redistributista \\
\cline { 2 - 2 } & 3 - Princípio reciprocio mercantírio ressignificado \\
\cline { 2 - 2 } & $4-$ Busca de investidores solidários \\
\hline Regulação Institucional & \\
\hline
\end{tabular}

Fonte: França Filho (2019).

Os dois níveis são denominados de regulação institucional e de reconstrução institucional, tanto para valorizar a importância da regulação como condição para o equilíbrio entre economia e sociedade, quanto para exprimir a inovação institucional necessária conforme indica a ideia de reconstrução. Os dois termos, aliás, são praticamente indivisíveis: a reconstrução institucional não deixa de ser uma regulação institucional, na medida em que ela implica um modo específico de operar, fundado num arcabouço institucional, bem como, um modo de provisão de bens e serviços. De todo modo, por regulação institucional entende-se a relação de mediação ou negociação com a economia pré-estabelecida e os potenciais agentes externos enquanto investidores. Essa visão da política pública não pretende fundá-la simplesmente na atração de investimentos privados externos, mas quer pensar sobre como esse investimento externo pode efetivamente favorecer o conjunto da sociedade local. Regulação, aqui entendida como mediação, é um modo de avaliar e corrigir possíveis efeitos de externalidade negativa do investimento e salientar o potencial de efeitos externalizadores positivos para o território (FRANÇA FILHO, 2019; EYNAUD, FRANÇA FILHO, 2019).

Como um determinado grande empreendimento privado pode oferecer contrapartidas à sociedade local em temos de reinvestimento? Quais as diferentes formas de investimento externo que não estão baseadas numa lógica de mercado convencional? Essas questões indicam alguns caminhos em termos de regulação institucional. Em complemento, por reconstrução institucional entende-se todos aqueles investimentos inovadores do ponto de vista do desenvolvimento das atividades (novos tipos de agentes ou atores socioeconômicos, novos tipos de arranjos ou redes inter-atores etc.). Enquanto a reconstrução institucional enfatiza o endógeno (ou a relação endógeno-exógeno), a regulação institucional lida fundamentalmente com o exógeno.

No que diz respeito aos eixos de intervenção, os três primeiros representam princípios de ação pública em matéria de reconstrução institucional: o princípio mercantil ressignificado; o princípio redistributivo; e o princípio reciprocitário. $O$ quarto eixo diz respeito à relação com os investidores externos e exprime uma modalidade de regulação institucional. Os quatro eixos de intervenção não devem ser concebidos isoladamente. Suas distinções revelam de maneira analítica a natureza específica de cada princípio econômico, mas suas complementaridades devem ser sublinhadas e valorizadas na prática. A tradução do conceito de economia plural permite não apenas modelizar as formas específicas de ação econômica, como também inventar formas de ação combinando a diversidade dos princípios econômicos. A implantação desses eixos não obedece a uma ordem particular a priori, nem a uma hierarquia qualquer. A maior ou menor importância acordada a cada um dos eixos é definida pela demanda e características do contexto local (FRANÇA FILHO, 2019; EYNAUD, FRANÇA FILHO, 2019). 


\section{Reconstrução institucional (1): o princípio mercantil ressignificado}

O primeiro eixo consiste em revalorizar o princípio mercantil no sentido de uma ressignificação de suas práticas. Para tanto, trata-se de introduzir mecanismos de cooperação e de solidariedade entre os agentes econômicos de mercado nas atividades locais de produção, de prestação de serviços, de comercialização, de consumo e de serviços financeiros. Esse eixo pressupõe dois aspectos. De um lado, enfatiza a necessidade de um suporte à criação e/ou consolidação de organizações de economia solidária. Ele conduz as políticas públicas a sustentar, nas suas ações, as cooperativas, as associações, as fundações e os empreendimentos econômicos solidários (EES). Por outro lado, a vocação de tais políticas deve ser ampla e incluir as iniciativas privadas com fins lucrativos que adotam ou empreendem modelos de negócios capazes de compartilhar ou de produzir efetiva distribuição de riqueza em seu contexto de inserção. O elemento comum aos dois aspectos é o compromisso com a territorialidade (FRANÇA FILHO, 2019; EYNAUD, FRANÇA FILHO, 2019).

O objetivo do eixo é de apoiar os atores que inovam, operando um trabalho de ressignificação das atividades de mercado. Os exemplos são numerosos e particularmente promissores, tanto no contexto nacional quanto na realidade internacional. Podemos salientar o caso do comércio justo e solidário, uma das primeiras práticas inovadoras neste sentido. As organizações do comércio justo se colocam, com efeito, no espaço do mercado para modificar suas regras por dentro. Com os seus produtos, eles quebram o livre jogo do mercado para inventar um novo enquadramento na origem das trocas mercantis, segundo regras sociais e ecológicas. Assim, o comércio justo trabalha com os pequenos produtores nos quais ele garante um preço fixo, em que poderão planificar razoavelmente suas economias domésticas (FRANÇA FILHO, 2019; EYNAUD, FRANÇA FILHO, 2019).

O preço de compra é, desse modo, subtraído, via regras auto-produzidas, dos mecanismos de livre fixação dos mercados. Um outro exemplo pode ser encontrado no âmbito dos chamados "circuitos curtos", na França, especialmente através das associações de manutenção da agricultura camponesa (AMAP association pour le maintien de l'agriculture paysanne). Estas associações criam um vínculo entre as áreas de exploração agrícola familiar com os coletivos de consumidores de suas vizinhanças. Trata-se de um acordo ou entendimento sobre a venda da produção em condições justas para o produtor. Este pode melhor planificar sua atividade e escapar dos ditames impostos pelos intermediários. Autoriza-se, neste caso, trocas de serviços gratuitos entre consumidores e produtores. Essa experiência tem se difundido mais recentemente em diferentes países, inclusive o Brasil, através da sigla CSA (consumidores sustentam agricultura).

No Brasil, experiências similares e menos recentes têm sido empreendidas, através dos chamados grupos de consumidores responsáveis e outras práticas de cooperativismo de consumo. De qualquer sorte, o conjunto de tais iniciativas se situam entre inúmeras outras experiências que na realidade brasileira participam do universo mais amplo das práticas de economia solidária, como as finanças solidárias através das cooperativas de crédito solidário, dos bancos comunitários de desenvolvimento e o uso de moedas sociais, dos fundos rotativos solidários, além de uma enorme diversidade de outras experiências indicando outras temáticas: turismo de base comunitária, empresas recuperadas, cooperativismo de plataforma etc. Nesse contexto, experiências de redes locais de economia solidária (FRANÇA FILHO, 2017) indicam importante potencial de contribuição.

\section{Reconstrução institucional (2): o princípio redistributista}

O segundo eixo de ação diz respeito ao melhor uso do potencial transformador do princípio redistributista, pela sua capacidade em gerar uma lógica de economia não mercantil ou de subsidiariedade (FRANÇA FILHO, 2019; EYNAUD, FRANÇA FILHO, 2019). As políticas públicas se encarregam, neste nível, de financiar via transferência de renda e/ou realocação de recursos atividades portadoras de forte potencial de 
impacto social em três domínios prioritários de investimentos: a) arte e cultura; b) esporte; e c) cuidados sociais mais amplos (que envolve principalmente a saúde, a educação e a assistência social). Trata-se de atividades incapazes de gerar, em muitos casos, todos os recursos de que necessitam através do seu próprio autofinanciamento, mas que possuem forte potencial de socialização e altíssimo grau de utilidade social em razão da amplitude da sua demanda. Elas contribuem com o fortalecimento dos vínculos sociais ou com a elevação do nível de conhecimento e formação das pessoas distanciadas da ação pública, ou ainda, com o necessário trabalho de reconhecimento e de identidade dos grupos e indivíduos marginalizados. O esforço da política pública se situa, então, no ponto cego das atividades de mercado e das análises clássicas do desenvolvimento territorial.

De forma mais objetiva e de maneira mais específica, a proposta deste eixo é de financiar atividades não geradoras de recursos próprios, mas com alto potencial de bem-estar social nos três âmbitos acima indicados, através de um criativo programa de bolsas auxílio e de apoio institucional. Ao menos cinco razões justificam um tal esforço de investimento: a) essas atividades constituem efetivas vocações profissionais para grande parte da população; b) expressam itinerários formativos altamente relevantes socialmente e devem poder representar carreiras profissionais atraentes; c) são atividades geradoras de identidades profissionais e de trabalho extremamente necessárias para a inclusão social e auto-estima individual; d) constituem demandas sociais de primeira ordem; e e) as rendas recebidas pelos profissionais em tais atividades retornam de maneira direta para as economias locais e podem realimentar um circuito econômico vigoroso, fortalecendo uma economia de bens relacionais com alto potencial de fomento ao desenvolvimento. Este tipo de suporte público participa de uma estratégia de longo prazo de revalorização do território e de apoio à sua população, para incluir suas áreas mais remotas e seu público mais vulnerável.

\section{Reconstrução institucional (3): o princípio reciprocitário}

O terceiro eixo de ação faz referência ao princípio reciprocitário, compreendendo notadamente uma lógica econômica não monetária e abrindo espaço para uma circulação monetária sem fins lucrativos, a exemplo das variadas formas de mutualização de recursos financeiros (FRANÇA FILHO, 2019; EYNAUD, FRANÇA FILHO, 2019). A política pública deve ajudar na estruturação tanto das atividades que escapam da circulação monetária, quanto daquelas que favorecem mecanismos de apropriação democrática dos recursos financeiros. Aqui reside um inventário muito amplo e variado de possibilidades, passando por diversas formas de mutualização de recursos, de ajuda mútua e de práticas de reciprocidade enquanto mecanismos de solidariedade econômica. Seja na forma de financiamentos coletivos, passando ainda por ações de mutirões, trata-se, na maioria das vezes, de ações coletivas de auto-organização permitindo inovar socialmente na resolução de problemas concretos afetando o cotidiano da vida das pessoas e grupos. Elas indicam formas de "economia mutuária", segundo a expressão de Guerreiro Ramos (1989).

Se tais ações dizem respeito às atividades mais conhecidas desde as últimas décadas no mundo - como os sistemas de trocas locais na França, ou sua modalidade semelhante em países anglófonos, na forma de bancos do tempo (Timebanks ou LETS - Local Exchange Trade System), que aliás encontra outras versões na América Latina através dos clubes de trocas -, elas também fazem alusão às formas ainda mais antigas em nossa realidade participando de uma tradição histórica de auto-organização do meio popular (mutirão, fundo de pasto), como também abrem caminhos para se pensar as novas possibilidades em torno das ferramentas digitais. As novas tecnologias podem trazer uma contribuição relevante no desenvolvimento de soluções criativas em matéria de reciprocidade. Neste âmbito, podemos citar as plataformas cooperativas, os aplicativos de compartilhamento (para deslocamento ou alojamento, entre outros) e que não entraram num circuito agressivo de mercado. Estas iniciativas participam do fortalecimento dos vínculos sociais e do enriquecimento da vida individual através da descoberta do outro. 
Regulação institucional: a busca de investidores solidários

Finalmente, o quarto eixo diz respeito à negociação com potenciais investidores externos (FRANÇA FILHO, 2019; EYNAUD, FRANÇA FILHO, 2019). Os atores públicos, numa estratégia de instauração de territórios solidários, são convidados a rever os elementos de apreciação e critérios de avaliação das contribuições esperadas ligadas aos investidores externos. Trata-se de vislumbrar não somente os pontos positivos ligados à chegada de novos capitais, mas também todos os efeitos deletérios no plano social, cultural ou ambiental. Um tal tipo de política é preventiva por natureza e objetiva zerar qualquer efeito de externalidade negativa. Ela privilegia investidores que venham para permanecer no território de maneira durável e, assim, poder engajar-se em iniciativas concernente o contexto local. Neste eixo aposta-se, ainda, em outras ações propondo soluções de reinvestimento local com participação ativa do agente externo, enquanto um modo de refazer o próprio princípio da redistribuição. $O$ intuito neste eixo é de realinhar uma ação que seria característica do segundo eixo, como um complemento a esse trabalho de atração do investimento externo.

Dois exemplos na França, a esse respeito, parecem particularmente relevantes. No primeiro caso, uma organização como Terres de Liens promove iniciativas de aquisição e recompra de áreas de exploração agrícola locais para evitar a especulação fundiária e garantir a permanência de pequenos agricultores nas suas terras. Terres de Liens é uma rede associativa surgida em 2003, associando uma organização de economia social e solidária e uma fundação. $O$ trabalho desta rede encontra-se na confluência de muitos campos como a educação popular, a agricultura orgânica e biodinâmica, a finança ética, a economia solidária e o desenvolvimento rural. No segundo exemplo, Habitat et Humanisme é uma organização de grande reconhecimento no âmbito do trabalho de gestão de obras sociais. Sua ação principal consiste em construir, comprar ou renovar imóveis voltados para o público constituído prioritariamente por pessoas e/ou grupos socialmente excluídos. Nos dois exemplos há, portanto, uma forte dinâmica de ação de financiamento em direção a um público que encontra dificuldades de se financiar pelos mecanismos convencionais de mercado. Tal dinâmica de financiamento vem adicionar-se ao trabalho de acompanhamento e apoio técnico (EYNAUD, FRANÇA FILHO, 2019).

\section{IV. À guisa de conclusão: globalizar a política, localizar a economia}

Diante da crise aguda da pandemia do coronavírus e do esgotamento crônico do modelo neoliberal pautado pelo divórcio entre economia e sociedade, impõe-se a tarefa de pensar um outro desenvolvimento (cf. MARTINS, 2019). Como mostramos, isso pressupõe um outro olhar sobre o que é o econômico, ensejando um conjunto renovado de práticas de ação pública na fronteira entre economia, solidariedade, democracia e territorialidade.

Em primeiro lugar, são necessárias formas de reapropriação da economia pela sociedade, o que depende de uma reversão da atual inversão da relação entre economia e política. É preciso que a política seja globalizada e a economia democratizada, de forma a retomar o poder político sobre os territórios, preservar a sócio-diversidade de nossas organizações (Laville, Young, Eynaud, 2015) e promover o desenvolvimento de uma para-economia (GUERREIRO RAMOS, 1981; FRANÇA FILHO, 2010; FRANÇA FILHO, BOULLOSA, 2015). Os rumos e as decisões equilibradas numa dinâmica econômica requerem dispositivos institucionais de natureza democrática, ou seja, demanda-se uma estrutura legal e jurídica que reconheça a necessidade de uma democratização, promova a descomodificação do mundo, proteja a biodiversidade e garanta a saída da era dos combustíveis fósseis. E, além disso, é fundamental que se opere uma territorialização da economia com um retorno às economia locais. Afinal de contas, "alguém duvida que são os próprios territórios que devem (ou deveriam) decidir democraticamente sobre as formas econômicas que irão melhor guiar seu desenvolvimento?" (FRANÇA FILHO, 2019, p.91).

Por fim, para que tenhamos sucesso na transição ecológica e social e sejam preservados os seres vivos na Terra, há pelo menos três condições necessárias, ainda que não suficientes: repensar a regulação 
econômica, estabelecer uma renda mínima e renda máxima e constituir um novo contrato social e natural. Para isso, é preciso atuar na implementação de políticas públicas ambiciosas em prol do apoio à economia social e solidária e ao início de uma real renovação da ação pública (LAVILLE, SALMON, 2015). É chegada a hora de avançar para um novo contrato natural (SERRES, 1991) e social (LAVILLE, ROUSTANG et al., 1996; ROSANVALLON, 2011), que seja capaz de garantir a permanência de uma vida feliz na terra.

\section{Referências}

ADORNO, Th., Estudos sobre a personalidade autoritária. São Paulo: Ed UNESP, 2019.

BONNEUIL, Ch.; FRESSOZ, J.-B. L'Événement Anthropocène : La Terre, l'histoire et nous, Paris: Seuil, 2013.

BURAWOY, M., "The Future of Sociology", Epilogue. In: Robert Brym (ed.), New Society, Nelson, 2013.

CAILLÉ, A. Critique de la raison utilitaire. Manifeste du MAUSS. Paris: La Découverte, 1988.

CHOMSKY, N. Who Rules the World?, Picador: USA, 2017.

CAPRARA, B., Thomas Piketty e "O Capital no Século XXl": da economia política à Sociologia contemporânea. Sociologias [online]. 2017, vol.19, n.44, p.424-439.

CLERO, J.P., "Jeremy Bantham (1748-1832) et le principe d'utilité", In: (CAILLÉ, LAZZERI, SENELLART (Orgs.), Histoire raisonnée de la philosophie morale et politique - le bonheur et l'utile. Paris: La Découverte, 2001. p.492-498.

DOWBOR, L. A era do capital improdutivo. São Paulo: Outras Palavras \& Autonomia Literária. 2017.

EPSTEIN, G.; MONTECINO, J. Overcharged: the High Cost of High Finance - The Roosevelt Institute, July 2016 - http://rooseveltinstitute.org/overcharged-high-cost-of-high-finance/

FOSSATI, E.C.; DEGRAVE, F.; LÉVESQUE, B., Innovations sociales transformatrices et transitions soutenables multi-niveaux: Dialogue entre deux approches complémentaires du changement social, 7ème Conférence EMES, 24-27 juin, 2019.

EYNAUD, P.; FRANÇA FILHO, G., Solidarité et organisation : penser une autre gestion, Toulouse: Érès Ed., 2019. 237p.

EYNAUD, P.; LAVILLE, J.-L. "Joining the commons with social and solidarity economy research: Towards the renewal of critical thinking and emancipation", Revista de Economia solidária, A Economia solidária e os comuns, vol. 11, 2018.

FRANÇA FILHO, G. "Decifrando a noção de paraeconomia em Guerreiro Ramos: a atualidade de sua proposição", Revista Organizações \& Sociedade (O\&S-EAUFBA), v.17, n.52, Jan./mar.2010.

FRANÇA FILHO, G.; BOULLOSA, R., Social Management and Para-Economy In: Laville, J.L., Young, D., Eynaud, P. (Orgs.), Civil Society, the Third Sector and Social Enterprise - Governance and democracy, New York: Routledge, 2015, p.222.-233.

FRANÇA FILHO, G., Economia e desenvolvimento. Salvador: UFBA. Escola de Administração, Superintendência de Educação à Distância (SEAD/UFBA), 2019. 97p. (Ebook).

FRANÇA FILHO, G., O imperativo de desenvolvimento territorial na economia solidária e o papel da incubadora tecnológica. In: Souza e Zanin (Orgs.), A economia solidária e os desafios globais do trabalho, 1ed., São Paulo: Edufscar, 2017, v.1, p.181-194. 
FRANÇA FILHO, G.; LAVILLE, J.L.. "Em tempos de pandemia, repensar a relação entre economia e sociedade". Le Monde Diplomatique Brasil. Acervo Online. 16.04.2020.

GAUCHET, M.. La démocratie contre elle-même. Paris: Gallimard, 2002.

GUERREIRO R., A., A nova ciência das organizações - uma reconceituação da riqueza das nações. São Paulo: FGV, 1989.

HAN, Byung-Chul. Sociedade do cansaço. Petrópolis, RJ: 2010.

HART, K., LAVILLE, J.L.; CATTANI, A.D. (editors), The Human Economy: A Citizen's Guide, Polity, 384 Pages, 2010.

HARVEY, David. O Neoliberalismo, história e implicações. São Paulo: Loyola, 2005.

HENRIQUES, A.; MALINA, A., Tecnologia para o desenvolvimento social: diálogos nides-ufrj, Editora Lutas Anticapital, Marília, 1a edição, 2018.

HILLENKAMP, I., LAVILLE, J.-L., Socioéconomie et démocratie: l'actualité de Karl Polanyi, Toulouse, érès. HIRSCHMAN, A. O. As Paixões e Os Interesses - Argumentos políticos a favor do capitalismo antes do seu triunfo. Rio de Janeiro: Record, 2002.

IPCC. Climate Change 2014: Synthesis Report. Contribution of Working Groups I, II and III to the Fifh Assessment Report of the Intergovernmental Panel on Climate Change [Core Writing Team, R.K. Pachauri and L.A. Meyer (eds.)]. IPCC, Geneva, Switzerland, 151 pp, 2014.

IPBES. Plate-forme intergouvernementale scientifique et politique sur la biodiversité et les services écosystémiques, Global Foodprint Network. 2017.

KLEIN, J.-L.; LAVILLE, J.-L.; MOULERT, F., L'innovation sociale, Toulouse, Erès, 2014.

LATOUCHE, S.; "Mandeville (1670-1732): le scandale de la prospérité du vice", In: (CAILLÉ, LAZZERI, SENELLART (Orgs.), Histoire raisonnée de la philosophie morale et politique - le bonheur et l'utile. Paris: La Découverte, 2001. p.409-413.

LAVILLE, J.-L; EYNAUD, P., Rethinking social enterprise through philanthropic and democratic solidarity. In: EYNAUD et al. Theory of social enterprise and pluralism: social movements, solidarity economy, and the global south, Routledge, p. 18-43, 2019.

LAVILLE, J.-L; ROUSTANG, G. et al., Vers un nouveau contrat social. Paris : Desclée de Brouwer, 1996.

LAVILLE, J.-L; SALMON, A., Associations et action publique, Paris, Desclée de Brouwer, 2015.

LAVILLE, J.-L; YOUNG, D.; EYNAUD, P. Civil Society, The Third Sector, Social Enterprise: Governance and Democracy, Routledge Publisher, Oxfordshire, 2015.

MAGNELLI, A.; MAIA, F.; CAMPOS, L, Uma democracia (in)acabada: quadros e bordas da soberania do povo com Pierre Rosanvallon. Rio de Janeiro: Ateliê de Humanidades, 2019.

MARCUSE, Herbert. O Homem Unidimensional: Estudos da Ideologia da Sociedade Industrial Avançada, São Paulo: Editora EDIPRO, 2015 [1964].

MARTINS, P. H., Teoria crítica da colonialidade. Rio de Janeiro: Ateliê de Humanidades, 2019.

MAUSS, M.., Ensaio sobre a dádiva (1923-1924). In: MAUSS, M. Sociologia e Antropologia. Cosac Naify, 2003.

OSTROM, E., Governing the Commons: The Evolution of Institutions for Collective Action (Political Economy of Institutions and Decisions), Cambridge University Press, 1990 
OSTROM, E., Understanding Institutional Diversity, Princeton/Oxford, Princeton University Press, 2005. OXFAM - Uma economia para os 99\% - resumo executivo em português, janeiro de 2017, https://www.oxfam.org.br/sites/ default/files/economia_para_99-sumario_executivo.pdf.

PICHOT, A. La société pure - De Darwin à Hitler. Paris:Flammarion, 2001.

PIKETTY, T. Le capital au XXI siècle. Paris, Le Seuil. 2013

POLANYI, K. A grande transformação: as origens da nossa época. Rio de Janeiro: Campus, 1986.

POLANYI, K., "La fallace économiste”, Bulletin du MAUSS, n 18, 1996.

POLANYI, K., A subsistência do homem - e ensaios correlatos, Rio de Janeiro, Contraponto, 2012.

ROSANVALLON, P. Le Capitalisme utopique. Histoire de l'idée de marché. Paris: Seuil, 1979.

ROSANVALLON, P. La Société des égaux. Paris: Seuil, 2011.

ROSANVALLON, P. Le siècle de populismes: Histoire, théorie, critique. Paris: Seuil, 2020.

SAQUET, M.A. Território. In: BOULLOSA, R.(Org.). Dicionário para a formação em gestão social. Salvador: Editora CIAGS/UFBA, 2014.

SERRES, M., Le Contrat naturel. Paris: Flammarion, 1990.

SERVIGNE, P., CHAPELLE; G. L'entraide, l'autre loi de la jungle. Paris, les liens qui libèrent. 